\title{
Direitos humanos, uma análise em tempos pandêmicos - Filosofia do Direito
}

\author{
Human rights, an analysis in pandemic times - Philosophy of Law \\ Derechos humanos, un análisis en tiempos de pandemia - Filosofía de Derecho
}

Recebido: 11/11/2021 | Revisado: 16/11/2021 | Aceito: 16/11/2021 | Publicado: 28/11/2021

\author{
Aline dos Santos Moreira de Carvalho \\ ORCID: https://orcid.org/0000-0001-9965-9566 \\ Universidad Columbia del Paraguay, Paraguai \\ E-mail: bioaline2017@yahoo.com \\ Evaldo Freires de Carvalho \\ ORCID: https://orcid.org/0000-0002-4539-8441 \\ Universidad Columbia del Paraguay, Paraguai \\ E-mail: evaldofreires@hotmail.com \\ Pedro Carlos Pereira \\ ORCID: https://orcid.org/0000-0003-4646-0080 \\ Universidade Federal Rural do Rio de Janeiro, Brasil \\ Universidad Columbia del Paraguay, Paraguai \\ E-mail: pecape@ig.com.br
}

\begin{abstract}
Resumo
Quando trabalhamos o conceito de Filosofia, nos deparamos com o estudo da existência humana. Na Filosofia do Direito, temos como objeto de reflexão, os Direitos Humanos, tão fundamentais para a formação do mundo contemporâneo e a criação das constituições que buscam defender a humanidade. A Declaração Universal dos Direitos Humanos é um marco inspirador de princípios que priorizam a paz, a cidadania e a democracia no mundo. Durante a pandemia da COVID-19 os Direitos Humanos tornaram-se intransponíveis e as normas internacionais obrigaram os governos a adotarem medidas para evitar ameaças à saúde pública. A Saúde é um direito de todos, assim como a Educação. A pandemia trouxe à tona a realidade há muito tempo vivida. A saúde é direito de todos, porém muitos brasileiros estão sem acesso a tratamentos e medicação. Assim como a educação, um problema sempre atual e pertinente, que enfrenta grandes desafios para alcançar os educandos que não possuem instrumentos tecnológicos que compreendem o necessário para as aulas remotas, online ou EAD (computador, celular, internet).
\end{abstract}

Palavras-chave: Direitos humanos; Educação; Filosofia; Pandemia.

\begin{abstract}
When we work on the concept of Philosophy, we are faced with the study of human existence. In the Philosophy of Law, our object of reflection is Human Rights, so fundamental to the formation of the contemporary world and the creation of constitutions that seek to defend humanity. The Universal Declaration of Human Rights is an inspiring framework for principles that prioritize peace, citizenship and democracy in the world. During the COVID-19 pandemic, human rights became insurmountable and international norms forced governments to adopt measures to avoid threats to public health. Health is everyone's right, as is Education. The pandemic has brought to light the long lived reality. Health is everyone's right, but many Brazilians do not have access to treatments and medication. As well as education, an always current and pertinent problem, which faces major challenges to reach students who do not have technological instruments that understand what is necessary for remote classes, online or distance learning (computer, cell phone, internet).
\end{abstract}

Keywords: Human rights; Education; Philosophy; Pandemic.

\section{Resumen}

Cuando trabajamos sobre el concepto de Filosofía, nos enfrentamos al estudio de la existencia humana. En la Filosofía del Derecho, nuestro objeto de reflexión son los Derechos Humanos, tan fundamentales para la formación del mundo contemporáneo y la creación de constituciones que busquen defender a la humanidad. La Declaración Universal de Derechos Humanos es un marco inspirador de principios que dan prioridad a la paz, la ciudadanía y la democracia en el mundo. Durante la pandemia de COVID-19, los derechos humanos se volvieron insuperables y las normas internacionales obligaron a los gobiernos a adoptar medidas para evitar amenazas a la salud pública. La salud es un derecho de todos, al igual que la educación. La pandemia ha sacado a la luz la larga realidad. La salud es un derecho de todos, pero muchos brasileños no tienen acceso a tratamientos y medicamentos. Así como la educación, un problema siempre actual y pertinente, que enfrenta grandes desafíos para llegar a los estudiantes que no cuentan con 
instrumentos tecnológicos que entiendan lo que es necesario para las clases remotas, en línea oa distancia (computadora, celular, internet).

Palabras clave: Derechos humanos; Educación; Filosofía; Pandemia.

\section{Introdução}

Filosofia é o campo de conhecimento que estuda a existência humana e o saber por meio de conhecimento racional e, como disciplina, responsável pela criação de conceitos. Nesse sentido, a Filosofia do Direito traz uma visão panorâmica e contextualizada do fenômeno jurídico, reconhecendo no próprio, sua natureza histórica. (Barros; Soares, 2015), objetivando uma reflexão acerca de algumas questões clássicas que se perpetuam como atuais, como é o caso dos Direitos Humanos tanto no aspecto de fundamentação teórica quanto na abertura e amplitude do conceito e de significados agregados ao longo da história.

Sobre os Direitos Humanos, Trindade (2007) discorre:

A proteção do ser humano contra todas as formas de dominação ou do poder arbitrário é da essência do Direito Internacional dos Direitos Humanos. Orientado essencialmente à proteção das vítimas, reais (diretas e indiretas) e potenciais, regula as relações entre desiguais, para os fins de proteção, e é dotado de autonomia e especificidade própria. (Trindade 2007, p. 210 apud Arifa, 2018).

Sendo assim, a questão dos Direitos Humanos e sua importância na formação do mundo contemporâneo estão amplamente ligadas com a criação das constituições e das leis que buscam defender e gerar a segurança para a humanidade que ocorreram ao longo do processo de formação da sociedade do século XXI.

Nesse contexto, e para o entendimento do que significa os Direitos Humanos como marco para a atual civilização, o presente estudo justifica-se pela necessidade de analisar os conceitos de Direitos Humanos, pontuando fatos histórico-culturais determinantes para o desenvolvimento desse, observando a ideologia iluminista e a influência de seus pensadores Adam Smith, John Locke e Rousseau, mencionando as defesas realizadas pelos pensadores Eleanor Roosevelt e Mahatma Gandhi e relacionando os Direitos Humanos, saúde e educação no atual cenário mundial (pandemia da COVID-19).

\section{Metodologia}

A metodologia utilizada neste estudo foi revisão de literatura, considerando como campo de pesquisa os Direitos Humanos e a Filosofia do Direito.

A seleção inicial incluiu publicações, estudos, periódicos e trabalhos acadêmicos, artigos acerca do tema e de seus aspectos relevantes, utilizando a palavras-chave como Direitos Humanos, Educação, Filosofia do Direito, Direitos Humanos, Eleanor Roosevelt, Iluminismo, Mahatma Gandhi, pandemia, saúde.

Foi realizada a pré-seleção excluindo textos que fugiam a temática central ou a área de conhecimento estudada.

Após a pré-seleção, foi feita a revisão literária incluindo pesquisa exploratória dos textos, pontuando as questões relevantes que compunha os objetivos propostos, relacionando fatores histórico-culturais, para compor os resultados e discussões que se seguem: contexto histórico-cultural, A Declaração Universal dos Direitos Humanos e a ONU, o Iluminismo e influência de Adam Smith, John Locke e Rousseau, Eleanor Roosevelt e Mahatma Gandhi, Pandemia e Direitos Humanos: saúde e educação.

\section{Dos Direitos Humanos}

Segundo Arifa (2018), o conceito de Direitos Humanos é fundamentalmente importante, porém sua abordagem pode ser feita de vários enfoques diferentes, de acordo com a esfera da vida em que está atuando. (ARIFA, 2018) 
A autora defende que uma conceituação pode ser feita a partir da seguinte classificação: direitos humanos como direito ou como processo e dinâmica social para a obtenção de direitos. Pela primeira, o conteúdo básico e tradicional são os direitos humanos em si mesmos; na segunda, os direitos humanos são resultados provisórios das lutas para se ter acesso aos bens necessários para a vida humana. (ARIFA, 2018)

Aos Direitos Humanos cabe ainda a definição pelas características apresentadas por Alexy (1999 apud ARIFA, 2018) que abrangem interesses e carências dos seres humanos (direitos fundamentais), ocupam uma posição de prioridade no sistema jurídico (direitos preferenciais), a validade é independente da positivação pela norma jurídica (direitos morais), a aplicação depende de alguma limitação no caso concreto (direitos abstratos) e têm por titulares todo e qualquer ser humano (universalidade). (ARIFA, 2018)

Diante da heterogeneidade de conceituação de Direitos Humanos, cabe buscar a fundamentação teórica desse para melhor entendimento dos aspectos constituintes de seu desenvolvimento.

\section{Contexto Histórico-cultural}

A história dos Direitos humanos inicia-se com o Cilindro de Ciro, na Babilônia. Porém, os primeiros documentos que afirmam os direitos individuais são a Carta Magna (1215), a Petição de Direito (1628), a Constituição dos Estados Unidos (1787), a Declaração Francesa dos Direitos do Homem e do Cidadão (1789), e a Declaração dos Direitos dos Estados Unidos (1791), considerados precursores escritos para muitos dos documentos de direitos humanos contemporâneos.

\section{A Magna Carta}

A Magna carta ou a Grande carta foi escrita e assinada pelo em 1215 por Rei João da Inglaterra, após a violação (por parte desse) de leis antigas. A carta é considerada a influência inicial e mais significativa para o que hoje é considerado como Direitos Humanos.

"enumera o que mais tarde veio a ser considerado como direitos humanos. Entre eles estava o direito da igreja de estar livre da interferência do governo, o direito de todos os cidadãos livres possuírem e herdarem propriedade, e serem protegidos de impostos excessivos. Isto estabeleceu o direito das viúvas que possuíam propriedade a decidir não voltar a casar-se, e estabeleceu os princípios de processos devidos e igualdade perante a lei. Isto também contém provisões que proíbem o suborno e a má conduta oficial." (Uma, on-line)

\section{A Petição de Direito}

A Petição de Direito foi feita em 1628 pelo Parlamento Inglês e enviada a Carlos I como uma declaração de liberdade civil. A petição fundamentou-se em estatutos e cartas anteriores e afirmou quatro princípios que são: nenhum tributo pode ser imposto sem o consentimento do Parlamento, nenhum súdito pode ser encarcerado sem motivo demonstrado (a reafirmação do direito de habeas corpus), nenhum soldado pode ser aquartelado nas casas dos cidadãos, e a Lei Marcial não pode ser usada em tempo de paz. (Uma, on-line).

\section{Declaração de Independência dos Estados Unidos}

Em 4 de julho de 1776, o Congresso dos Estados Unidos assinou a Declaração de Independência, anunciando que as treze colônias não faziam mais parte do Império Britânico.

Essa Declaração acentuou os direitos individuais e o direito de revolução (influenciando a Revolução Francesa), em uma análise filosófica. 


\section{A Declaração dos Direitos do Homem e do Cidadão}

Em 1789, o povo francês aboliu a monarquia absoluta e estabeleceu a primeira república francesa, e a Declaração dos Direitos do Homem e do Cidadão foi recebida pela Assembleia Constituinte como o primeiro passo para a constituição de uma república francesa.

Segundo o autor,

A Declaração proclama que todos os cidadãos devem ter garantidos os direitos de liberdade, propriedade, segurança, e resistência à opressão. Isto argumenta que a necessidade da lei provém do facto que o exercício dos direitos naturais de cada homem tem só aquelas fronteiras que asseguram a outros membros da sociedade o desfrutar destes mesmos direitos. Portanto, a Declaração vê a lei como uma expressão da vontade geral, que tem a intenção de promover esta igualdade de direitos e proibir só acções prejudiciais para a sociedade. (Uma, on-line)

\section{A Declaração Universal dos Direitos Humanos e a ONU}

Em 1945, cinquenta nações reuniram-se em San Francisco e formaram a Organização das Nações Unidas para proteger e promover a paz, durante a Segunda Guerra Mundial.

Em 1848, a comissão de Direitos Humanos da ONU tinha conseguido atenção mundial, e devido a defesa da presidente Eleanor Roosevelt, elaborou um documento que se tornaria a Declaração Universal dos Direitos Humanos, que foi adotada pela ONU em 10 de dezembro de 1948.

A Declaração Universal dos Direitos Humanos é um marco inspirador de princípios que priorizam a paz, a cidadania e a democracia no mundo; é um documento que delimita os direitos fundamentais do ser humano.

A Declaração Universal dos Direitos Humanos compreende:

\section{Objetivos:}

"A presente Declaração Universal dos Direitos Humanos como o ideal comum a ser atingido por todos os povos e todas as nações, com o objetivo de que cada indivíduo e cada órgão da sociedade, tendo sempre em mente esta Declaração, se esforce, através do ensino e da educação, por promover o respeito a esses direitos e liberdades, e, pela adoção de medidas progressivas de caráter nacional e internacional, por assegurar o seu reconhecimento e a sua observância universal e efetiva, tanto entre os povos dos próprios Estados-membros, quanto entre os povos dos territórios sob sua jurisdição.

\section{- $\quad$ Artigo I}

Todas as pessoas nascem livres e iguais em dignidade e direitos. São dotadas de razão e consciência e devem agir em relação umas às outras com espírito de fraternidade.

\section{- $\quad$ Artigo II}

1 - Toda pessoa tem capacidade para gozar os direitos e as liberdades estabelecidas nesta Declaração, sem distinção de qualquer espécie, seja de raça, cor, sexo, língua, religião, opinião política ou de outra natureza, origem nacional ou social, riqueza, nascimento, ou qualquer outra condição.

2 - Não será tampouco feita qualquer distinção fundada na condição política, jurídica ou internacional do país ou território a que pertença uma pessoa, quer se trate de um território independente, sob tutela, sem governo próprio, quer sujeito a qualquer outra limitação de soberania.

\section{- $\quad$ Artigo III}

Toda pessoa tem direito à vida, à liberdade e à segurança pessoal.

\section{- $\quad$ Artigo IV}

Ninguém será mantido em escravidão ou servidão; a escravidão e o tráfico de escravos serão proibidos em todas as suas formas.

\section{- Artigo V}

Ninguém será submetido à tortura, nem a tratamento ou castigo cruel, desumano ou degradante.

- Artigo VI

Toda pessoa tem o direito de ser, em todos os lugares, reconhecida como pessoa perante a lei.

- $\quad$ Artigo VII 
Todos são iguais perante a lei e têm direito, sem qualquer distinção, à igual proteção da lei. Todos têm direito à igual proteção contra qualquer discriminação que viole a presente Declaração e contra qualquer incitamento a tal discriminação.

\section{- $\quad$ Artigo VIII}

Toda pessoa tem direito a receber dos tribunais nacionais competentes remédio efetivo para os atos que violem os direitos fundamentais que lhe sejam reconhecidos pela constituição ou pela lei.

\section{- $\quad$ Artigo IX}

Ninguém será arbitrariamente preso, detido ou exilado.

\section{- $\quad$ Artigo X}

Toda pessoa tem direito, em plena igualdade, a uma audiência justa e pública por parte de um tribunal independente e imparcial, para decidir sobre seus direitos e deveres ou do fundamento de qualquer acusação criminal contra ele.

\section{- Artigo XI}

1 - Toda pessoa acusada de um ato delituoso tem o direito de ser presumida inocente até que a sua culpabilidade tenha sido provada de acordo com a lei, em julgamento público no qual lhe tenham sido asseguradas todas as garantias necessárias à sua defesa.

$\mathbf{2}$ - Ninguém poderá ser culpado por qualquer ação ou omissão que, no momento, não constituíam delito perante o direito nacional ou internacional. Tampouco será imposta pena mais forte do que aquela que, no momento da prática, era aplicável ao ato delituoso.

\section{- $\quad$ Artigo XII}

Ninguém será sujeito a interferências na sua vida privada, na sua família, no seu lar ou na sua correspondência, nem a ataques à sua honra e reputação. Toda pessoa tem direito à proteção da lei contra tais interferências ou ataques.

\section{- Artigo XIII}

1 - Toda pessoa tem direito à liberdade de locomoção e residência dentro das fronteiras de cada Estado.

2 - Toda pessoa tem o direito de deixar qualquer país, inclusive o próprio, e a este regressar.

\section{- $\quad$ Artigo XIV}

1 - Toda pessoa, vítima de perseguição, tem o direito de procurar e de gozar asilo em outros países.

$\mathbf{2}$ - Este direito não pode ser invocado em caso de perseguição legitimamente motivada por crimes de direito comum ou por atos contrários aos propósitos e princípios das Nações Unidas.

\section{- Artigo XV}

1 - Toda pessoa tem direito a uma nacionalidade.

2 - Ninguém será arbitrariamente privado de sua nacionalidade, nem do direito de mudar de nacionalidade.

\section{- $\quad$ Artigo XVI}

1 - Os homens e mulheres de maior idade, sem qualquer restrição de raça, nacionalidade ou religião, têm o direito de contrair matrimônio e fundar uma família. Gozam de iguais direitos em relação ao casamento, sua duração e sua dissolução.

2 - O casamento não será válido senão como o livre e pleno consentimento dos nubentes.

3 - A família é o núcleo natural e fundamental da sociedade e tem direito à proteção da sociedade e do Estado.

\section{- Artigo XVII}

1 - Toda pessoa tem direito à propriedade, só ou em sociedade com outros.

2 - Ninguém será arbitrariamente privado de sua propriedade.

\section{- $\quad$ Artigo XVIII}

Toda pessoa tem direito à liberdade de pensamento, consciência e religião; este direito inclui a liberdade de mudar de religião ou crença e a liberdade de manifestar essa religião ou crença, pelo ensino, pela prática, pelo culto e pela observância, isolada ou coletivamente, em público ou em particular.

\section{- Artigo XIX}

Toda pessoa tem direito à liberdade de opinião e expressão; este direito inclui a liberdade de, sem interferência, ter opiniões e de procurar, receber e transmitir informações e ideias por quaisquer meios e independentemente de fronteiras.

\section{- $\quad$ Artigo XX}

1 - Toda pessoa tem direito à liberdade de reunião e associação pacíficas

1 - Ninguém pode ser obrigado a fazer parte de uma associação.

\section{- $\quad$ Artigo XXI}


1 - Toda pessoa tem o direito de tomar parte no governo de seu país, diretamente ou por intermédio de representantes livremente escolhidos.

2 - Toda pessoa tem igual direito de acesso ao serviço público do seu país.

3 - A vontade do povo será a base da autoridade do governo; esta vontade será expressa em eleições periódicas e legítimas, por sufrágio universal, por voto secreto ou processo equivalente que assegure a liberdade de voto.

\section{- $\quad$ Artigo XXII}

Toda pessoa, como membro da sociedade, tem direito à segurança social e à realização, pelo esforço nacional, pela cooperação internacional de acordo com a organização e recursos de cada Estado, dos direitos econômicos, sociais e culturais indispensáveis à sua dignidade e ao livre desenvolvimento da sua personalidade.

\section{- $\quad$ Artigo XXIII}

1 - Toda pessoa tem direito ao trabalho, à livre escolha de emprego, a condições justas e favoráveis de trabalho e à proteção contra o desemprego.

2 - Toda pessoa, sem qualquer distinção, tem direito à igual remuneração por igual trabalho.

3 - Toda pessoa que trabalha tem direito a uma remuneração justa e satisfatória, que lhe assegure, assim como à sua família, uma existência compatível com a dignidade humana, e a que se acrescentarão, se necessário, outros meios de proteção social.

4 - Toda pessoa tem direito a organizar sindicatos e a neles ingressar para a proteção de seus interesses.

\section{- $\quad$ Artigo XXIV}

Toda pessoa tem direito a repouso e lazer, inclusive à limitação razoável das horas de trabalho e a férias periódicas remuneradas.

\section{- $\quad$ Artigo XXV}

1 - Toda pessoa tem direito a um padrão de vida capaz de assegurar a si e a sua família saúde e bem-estar, inclusive alimentação, vestuário, habitação, cuidados médicos e os serviços sociais indispensáveis, e direito à segurança em caso de desemprego, doença, invalidez, viuvez, velhice ou outros casos de perda dos meios de subsistência em circunstâncias fora de seu controle.

$\mathbf{2}$ - A maternidade e a infância têm direito a cuidados e assistência especiais. Todas as crianças, nascidas dentro ou fora de matrimônio, gozarão da mesma proteção social.

\section{- $\quad$ Artigo XXVI}

1 - Toda pessoa tem direito à instrução. A instrução será gratuita, pelo menos nos graus elementares e fundamentais. A instrução elementar será obrigatória. A instrução técnicoprofissional será acessível a todos, bem como a instrução superior, esta baseada no mérito.

$\mathbf{2}$ - A instrução será orientada no sentido do pleno desenvolvimento da personalidade humana e do fortalecimento do respeito pelos direitos humanos e pelas liberdades fundamentais. A instrução promoverá a compreensão, a tolerância e a amizade entre todas as nações e grupos raciais ou religiosos, e coadjuvará as atividades das Nações Unidas em prol da manutenção da paz.

3 - Os pais têm prioridade de direito na escolha do gênero de instrução que será ministrada a seus filhos.

\section{- $\quad$ Artigo XXVII}

1 - Toda pessoa tem o direito de participar livremente da vida cultural da comunidade, de fruir as artes e de participar do processo científico e de seus benefícios.

$\mathbf{2}$ - Toda pessoa tem direito à proteção dos interesses morais e materiais decorrentes de qualquer produção científica, literária ou artística da qual seja autor.

\section{- Artigo XXVIII}

Toda pessoa tem direito a uma ordem social e internacional em que os direitos e liberdades estabelecidos na presente Declaração possam ser plenamente realizados.

\section{- $\quad$ Artigo XXIX}

1 - Toda pessoa tem deveres para com a comunidade, em que o livre e pleno desenvolvimento de sua personalidade é possível.

2 - No exercício de seus direitos e liberdades, toda pessoa estará sujeita apenas às limitações determinadas por lei, exclusivamente com o fim de assegurar o devido reconhecimento e respeito dos direitos e liberdades de outrem e de satisfazer às justas exigências da moral, da ordem pública e do bem-estar de uma sociedade democrática.

3 - Esses direitos e liberdades não podem, em hipótese alguma, ser exercidos contrariamente aos propósitos e princípios das Nações Unidas.

\section{- $\quad$ Artigo XXX}

Nenhuma disposição da presente Declaração pode ser interpretada como o reconhecimento a qualquer Estado, grupo ou pessoa do direito de exercer qualquer atividade ou praticar qualquer ato 
destinado à destruição de quaisquer dos direitos e liberdades aqui estabelecidos.” (Humanos, 1948 apud Ribeiro, on - line)

O Iluminismo e influência de Adam Smith, John Locke e Rousseau

O Iluminismo foi um movimento cultural europeu do século XVII e XVIII que objetivava mudanças políticas, econômicas e sociais na sociedade.

Dentre alguns aspectos, os iluministas acreditavam na multiplicação do conhecimento, como forma de sobrepor a razão ao pensamento religioso. Dentre algumas vertentes, o Iluminismo Político defende os direitos que seriam indissociáveis da condição humana, trabalhando conceitos como liberdade e igualdade, que implicou no estreitamento da relação entre a democracia e os direitos humanos.

A concepção iluminista de Direito observa desde o direito à integridade até participar ativamente da escolha do seu futuro e do futuro da sociedade que integra.

Nesta senda, a divisão de poderes, ou como pretendem alguns, a repartição de competências de seu exercício, se evidencia como o mais eficaz mecanismo de tutela dos direitos humanos e da democracia.

Tome-se a liberdade material como corolário inarredável dos direitos humanos. Entende-se, ainda, que a divisão de poderes carrega consigo a finalidade precípua de limitação da autoridade. Nesse quadro, conclui-se que uma adequada compartimentalização de competências propicia uma eficaz tutela dos direitos humanos. (Santos, 2012, on-line)

Dentre os pensadores iluministas que defendiam ideais próximos à ideologia de igualdade e liberdade estão Adam Smith, John Locke e Rousseau, considerados precursores do liberalismo político (o Estado tem poderes e função limitados; filosoficamente, doutrina que defende os direitos naturais do homem, autônomo e independente).

\title{
Eleanor Roosevelt e Mahatma Gandhi
}

\begin{abstract}
"A liberdade faz uma exigência enorme a cada ser humano. Com a liberdade vem a responsabilidade. Para a pessoa que está relutante em crescer, para a pessoa que não quer carregar o seu próprio fardo, esta é uma perspectiva assustadora." (Roosevelt, online apud Defensores, on-line)
\end{abstract}

Eleanor Roosevelt foi presidente da Comissão de Direitos Humanos da Nações Unidas e impulsionou a criação da carta que deu origem a Declaração Universal dos Direitos do Homem. Defendia que era necessário a mobilização pela paz universal e acreditava que a democracia era muito importante. (Defensores, on-line)

Em seu legado estão o combate às desigualdades de gênero e aos mais variados tipos de preconceitos religiosos e lutou até o fim de sua vida para que os direitos estabelecidos na declaração fossem aceitos e implementados. (Defensores, on line)

"Quando em desespero, lembro-me que ao longo de toda a história os caminhos da verdade e do amor ganharam sempre. Existiram tiranos e assassinos e durante um período eles podem parecer invencíveis, mas no final eles caem sempre. Pensem nisso - sempre" (Gandhi, online apud Defensores, on-line).

Mohandas Karamchand Gandhi ficou conhecido mundialmente por ser um dos maiores líderes político do século XX e foi pioneiro e praticou a desobediência civil não violenta, sempre liderando campanhas nacionais contra a pobreza, expandir os direitos das mulheres e criar harmonia religiosa e étnica, e eliminar injustiças. (Defensores, on-line)

Nesse contexto, pode-se dizer que essas duas pessoas foram defensoras dos Direitos Humanos, e suas participações foram de extrema importância para que existisse uma sociedade menos preconceituosa, racista e xenofóbica. 


\section{Direitos Humanos, saúde e educação no atual cenário mundial (pandemia da COVID-19)}

Durante a pandemia da COVID-19, os Direitos Humanos, tornaram-se intransponíveis. As normas internacionais obrigam os governos a adotarem medidas para evitar ameaças à saúde pública bem como prestarem assistência médica a todos quantos necessitam.

A ONU determinou para o cumprimento das obrigações do Pacto por parte dos Estados, que:

O direito à saúde está intimamente relacionado e dependente do respeito a outros direitos humanos, contidos na Declaração Universal dos Direitos Humanos, incluindo os direitos à alimentação, moradia, trabalho, educação, dignidade humana, vida, não-discriminação, igualdade, a proibição da tortura, privacidade, acesso à informação, e as liberdades de associação, assembleia e movimento. Esses e outros direitos e liberdades orientam elementos integrais do direito à saúde. (ONU, 2020 apud Dimensões, 2020)

Diante da afirmativa, cabe aos governos a observância quanto ao direito à saúde e ao direito à educação.

No caso brasileiro, a pandemia trouxe à tona a realidade há muito tempo vivida: a desigualdade social, que neste momento está multiplicando-se desordenadamente e atingindo avassaladoramente tanto a saúde quanto a educação.

A saúde é direito de todos, porém muitos brasileiros estão sem acesso a tratamentos e medicação, inclusive a vagas em UTIs e leitos em enfermarias hospitalares.

Assim como a educação, um problema sempre atual e pertinente, que no atual momento enfrenta grandes desafios para alcançar os educandos que não possuem instrumentos tecnológicos que compreendem o necessário para as aulas remotas, online ou EAD (computador, celular, internet).

\section{Considerações Finais}

Os Direitos Humanos e a observância desses estão intimamente ligados ao desenvolvimento e evolução da sociedade contemporânea, e do ser humano individualmente e como parte de um todo.

A Declaração Universal dos Direitos Humanos foi um marco ímpar na história da humanidade e a filosofia aliada ao Direito contribui para que os direitos sejam resguardados, principalmente os de igualdade e liberdade fundamentais para a democracia.

Analisando o contexto histórico cultural, relacionado com a ideologia iluminista e seus pensadores (liberalismo político) e observando a necessidade humana de defender seus direitos representados por pessoas como Eleanor Roosevelt e Mahatma Gandhi, pode-se concluir que os anseios de liberdade e igualdade são intrínsecos à essência humana e, portanto, precisam ser protegidos assim como todos os outros Direitos Humanos pontuados.

No atual momento pandêmico, assiste-se aos gritos das desigualdades que por muitos anos camufladas, encontram-se inflamadas diante as extremas necessidades oriundas da situação de crise, principalmente com relação à saúde e a educação.

\section{Referências}

Almeida, F. (2020). Para uma filosofia dos Direitos Humanos. https://nidh.com.br/para-uma-filosofia-dos-direitos-humanos/.

Arifa, B. I. A. O conceito e o discurso dos Direitos Humanos: realidade ou retórica? Boletim Científico ESMPU, 17(51), 145-173 https://escola.mpu.mp.br/publicacoes/boletim-cientifico/edicoes-do-boletim/boletim-cientifico-n-51-janeiro-junho-2018/o-conceito-e-o-discurso-dos-direitoshumanos-realidade-ou-retorica/at_download/file>.

Ávila, H., \& Sánchez, L. C. (2011). Teoría de los principios. Marcial Pons

Bello, E.; Bercovici, G.; \& Lima, M. M.'A. B. O Fim das Ilusões Constitucionais de 1988? Revista Direito e Práxis. 10(3), 1769-1811, https://www.scielo.br/scielo.php?pid=S2179-89662019000301769\&script=sci_arttext.

Barros, F. A., \& Soares, T. T. Filosofia do Direito: A importância do estudo da filosofia para o Direito. Jus.com.br. https://jus.com.br/artigos/74228/filosofiado-direito>.

Barroso, L. R. (2019). O controle de constitucionalidade no direito brasileiro. (8a ed.), Saraiva Educação AS. 
Research, Society and Development, v. 10, n. 15, e362101523180, 2021

(CC BY 4.0) | ISSN 2525-3409 | DOI: http://dx.doi.org/10.33448/rsd-v10i15.23180

Brasil. Constituição (1988). Constituição da República Federativa do Brasil. Senado Federal: Centro Gráfico, 1988.

Brasil. Lei $\mathrm{N}^{\circ}$ 13.979, de 6 de fevereiro de 2020. Dispõe sobre as medidas para enfrentamento da emergência de saúde pública de importância internacional decorrente do coronavírus responsável pelo surto de 2019. Brasília: Presidência da República, Casa Civil, Subchefia para Assuntos Jurídicos, [2020a]. http://www.planalto.gov.br/ccivil_03/_ato2019-2022/2020/lei/L13979compilado.htm.

Defensores dos Direitos Humanos. Unidos pelos direitos humanos. Online. https://www.unidosparaosdireitoshumanos.com.pt/voices-for-humanrights/mahatma-gandhi.html>.

Dimensões de Direitos Humanos na resposta à COVID-19. Humam Rights Watch. 2020. https://www.hrw.org/pt/news/2020/03/23/339654

Freire, Paulo. Pedagogia da indignação: cartas pedagógicas e outros escritos. São Paulo: Editora UNESP, 2000.

Henrique, T. COVID-19 e a Internet (ou estou em isolamento social físico). Interfaces Científicas - Humanas e Sociais, Aracaju, 8(3), 173-176 ONU. World Economic Situation and Prospects as of mid-2020. Folha informativa. Nova Iorque, 2020, on-line.

OMS. Global scientific community unites to track progress on COVID-19 R\&D, identifies new research priorities and critical gaps. Folha informativa. Geneva, 2 july 2020. Newsroom, on-line.

OMS. WHO Director-General's opening remarks at the media briefing on COVID-19. Folha informativa. Newsroom. https://www.who.int/dg/speeches/detail/who-director-general-s-opening-remarks-at-the-media-briefing-on-covid-19--13-april-2020.

Ribeiro, A. "Declaração Universal dos Direitos Humanos"; Brasil Escola. online. https://brasilescola.uol.com.br/geografia/declaracao-universal-dos-direitoshumanos.htm.

Santos, A. M. B. P. Iluminismo político: a libertação do homem pelo Direito. Jus.com.br. 2012. Disponível em:< https://jus.com.br/artigos/23331/iluminismopolitico-a-libertacao-do-homem-pelo-direito>.

Santos, E. O; Carvalho, F. S.; \& Pimentel, M. Mediação docente online para colaboração: notas de uma pesquisa-formação na cibercultura. ETD - Educação Temática Digital, 18(1), 23-42, 2016.

Santos, E. O. EAD, palavra proibida. Educação online, pouca gente sabe o que é. Ensino remoto, o que temos para hoje. Mas qual é mesmo a diferença? \#livesdejunho... Revista Docência e Cibercultura. Notícias. 2020.

Uma breve história dos direitos humanos. Unidos pelos direitos humanos. https://www.unidosparaosdireitoshumanos.com.pt/what-are-human-rights/briefhistory/. 